\title{
Author Correction to: L-Acetyl-carnitine in Patients with Carpal Tunnel Syndrome: Effects on Nerve Protection, Hand Function and Pain
}

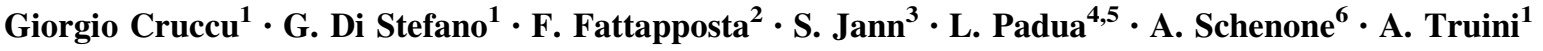

Published online: 13 February 2018

(C) Springer International Publishing AG, part of Springer Nature 2018

\section{Author Correction to: CNS Drugs (2017) 31: \\ 1103-1111 https://doi.org/ \\ 10.1007/s40263-017-0476-2}

In the original publication the name of third author was incorrectly published.

Page 1103, author listing: The name of the third author, which previously read:

"F. Fattaposta"

should read:

"F. Fattapposta".

The original article can be found online at https://doi.org/10.1007/ s40263-017-0476-2.

Giorgio Cruccu

giorgio.cruccu@uniroma1.it

1 Department of Neurology and Psychiatry, Sapienza

University, Viale Università 30, 00185 Roma, Italy

2 Policlinico Umberto I, Sapienza University, Roma, Italy

3 Department of Neuroscience, Niguarda Hospital, Milano, Italy

4 Department of Geriatrics, Neurosciences and Orthopaedics, Università Cattolica del Sacro Cuore, Rome, Italy

5 Department of Neurorehabilitation, Don Carlo Gnocchi Onlus Foundation, Milan, Italy

6 Department of Neuroscience, Rehabilitation, Ophthalmology, Genetics, Maternal and Child Health (DiNOGMI), University of Genova, Genova, Italy 